\title{
Applying Process Data Warehouse in Analysis of Business Processes Success Rate
}

\author{
Miomir Rakić \\ Phd Student \\ Energoprojekt Energodata \\ Belgrade, Serbia
}

\author{
Dušan Regodić \\ Phd, University Singidunum \\ Belgrade, Serbia
}

\author{
Gojko Grubor \\ Phd, University Sinergija \\ Bjeljina, Bosnia and Hercegovina
}

\begin{abstract}
In order for company could to devote its primary goal, constant improvement and review in all areas relating to the effectiveness and efficiency of the implementation of all processes within the system, it is necessary to adopt certain methodologies, methods, techniques and tools that will allow them to. One approach is the application of data warehouse database, or the process warehouse-a (PW) as a specific sub-type that allows data have been incurred in the daily work process at the process level, not at the level of individual actions or events within the system.

The results of these analyzes are the basis for the analysis, improvement and correction processes, sub-processes, activities, and a combination of activities that constitute a specific measurable unit.

By analyzing the successful realization of the goals, conclusions were drawn that at certain results when the objective is met, the subsequent analysis process to determine that although the goal is achieved, the final result of the success of achieving this goal is not optimal and extremely dysfunctional for a service that provides maintenance of equipment.
\end{abstract}

\section{Keywords}

Process Data Warehouse, Business Intelligence, Business Process Management, analyzing and improvement of processes

\section{INTRODUCTION}

In current world's economy, companies are every day under great pressures struggling for survival. They try to balance between profit and services qualities. Therefore, they have to analyze reassess and improve processes, making them economic, effective and efficient in business system, as much as possible. Analysis of the cost effectiveness of the process and objectives of contractual obligations fulfillment can be a way to improve business.

In order to perform processes analysis, as the first step it is necessary to analyze and choose appropriate techniques that can enable accurate and quality method to select process, to analyze it and to recognize its data, after that. An adequate data base and tools for timely and detailed process analysis must be selected, too. This previous analysis is basis for process, its sub processes and activities correction and improvement, later on.

As the next step, there is need to select appropriate process modeling language and tool for its full implementation, and a sufficiently adaptive methodology for data analysis that enables at least relation and multidimensional data base structuring.

After all of these analyses, selection of data base structure that is optimal for process analysis, without additional coding, must be performed. In this framework a broader assessment of data usability, availability and completeness, and defining missing data and their entry into reporting system later on, were necessary to be performed, too.

Finally there was need to select a tool to perform adapted analysis that provides clear, viewed and timely reporting.

\section{SELECTION OF METHODOLOGY AND LANGUAGE FOR PROCESS MODELING}

To select methodology for data warehouse (DW) development was necessary to choose best language for DW model development [1]. However, some previous decisions have to be done, such as:

- $\quad$ The DW was selected between Relational (Fig. 1) and DW model of DB (Fig. 2),

- The Kimball method was selected instead of Inmon,

- Process DW (PDW) was selected as type of DW, and

- The Goal Driven (GD) sub type of PDW was selected instead of Goal Oriented Design (GoD).

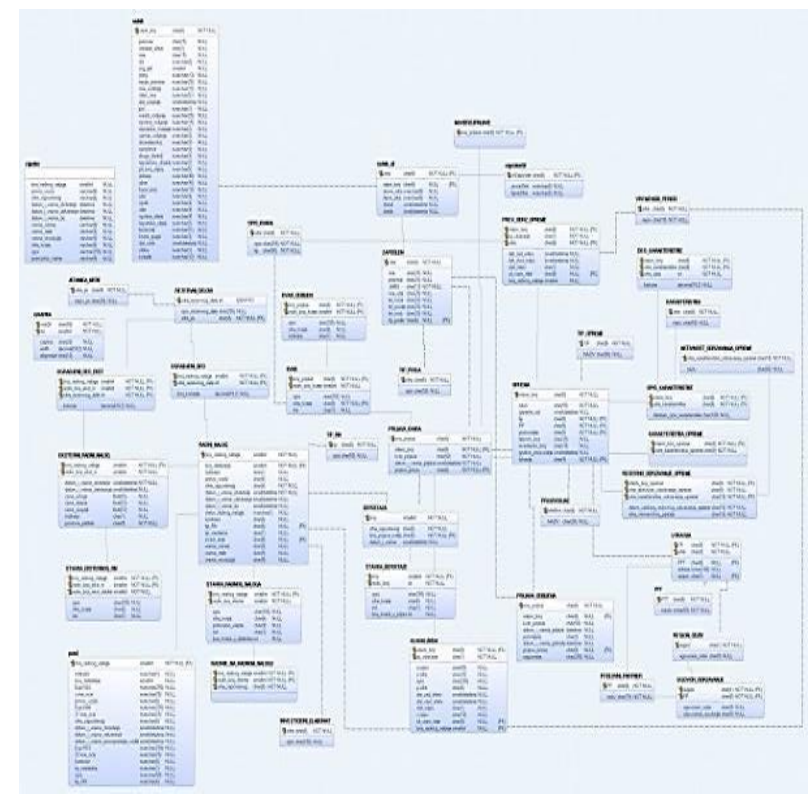

Fig 1 Example of relational DB model

As result of languages analysis the Business Process Modeling Language (BPML) was chosen among available ones [2]. Current process modeling languages can be divided into: (1) Traditional languages; (2) Object Oriented languages; (3) Dynamic Modeling languages, and (4) Processes Integration languages. As modeling languages, a set of IDEF methods and standards 
was selected. The IDEF0 standard was selected for process modeling (Fig. 3), and IDEF1X - for data modeling [3]. This choice has been performed based on Bung Wand Weber (BWW) concept of ontology integrity [4], Curtis \& all works [5], and on experience of the authors of this paper, as well.

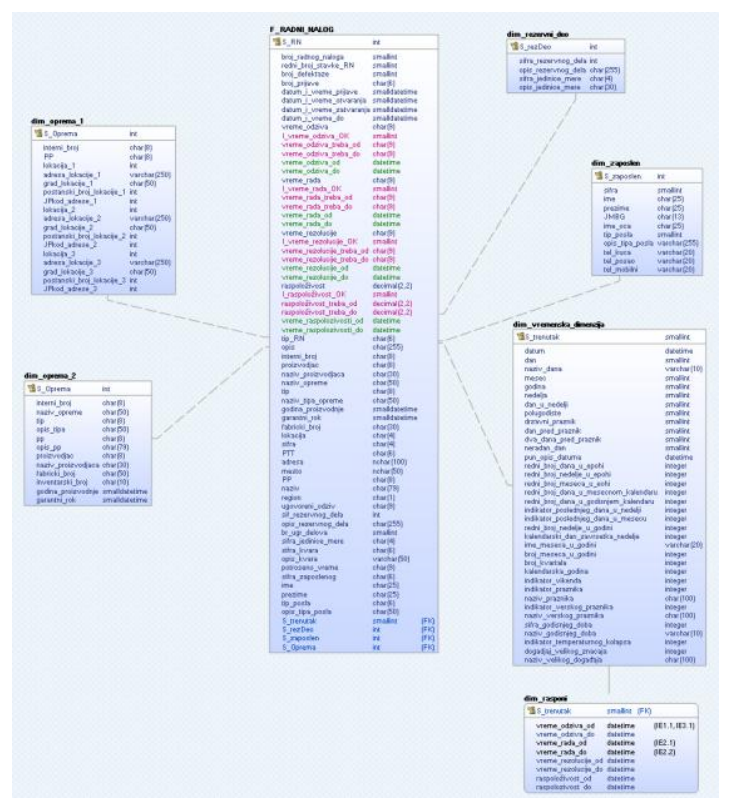

Fig 2 Example of multidimensional DB model

\section{PROCESS PERFORMANCE ANALY- SIS AND IMPROVEMENT}

Main goal of analyzing performances of the processes and activities is to recognize those elements that fail to achieve values of objectives or that are delayed, or declined from statistic deviation of the processes.

In order to start process analysis and improvement it was necessary to identify the following:

- Resources and agents that belong to an activity. They are represented by arrow from lower, top and left sides in IDEF0 model. The arrow from lower side represents resources needed to start activity. The agents from left side start activity but they will be transformed into another agent or material form by activity itself. The agents from top side are triggers for activity performance that won't be transformed by activity itself, or they are activity control agents.

- Potential changes inside current processes, sub processes and activities structures.

- Besides analysis of values that are measured, it was necessary to define reference values on which analysis can be performed. This must be done during defining objectives, their key performance indicators (KPI), target wanted values, and combination of objectives, success rate indicators, and triggers and resources for process or activity performance, as well.

\section{BUILDING OBJECTIVE STRUCTURE AND ITS INTEGRATION INTO PROCESS STRUCTURE}

Objective and process structures should be building at the same time, generating parallel objective decomposition tree. The decomposition tree is made according to certain rules that are based on main objective or root, sub objectives and atomic objective at lowest level, and operator for objective decomposition, as well.

Defined objectives can be divided into internal and external. Companies generate the internal objectives that can be changed depending of situation and analysis specificity. The external objectives are defined by contract between two participants in process that are primary responsible for objective achievement. For any objective some parameters must be determined such as its range, bitmap indicator (indicates objective achievement), written or measured current value, and objective validity expired time must be determined.

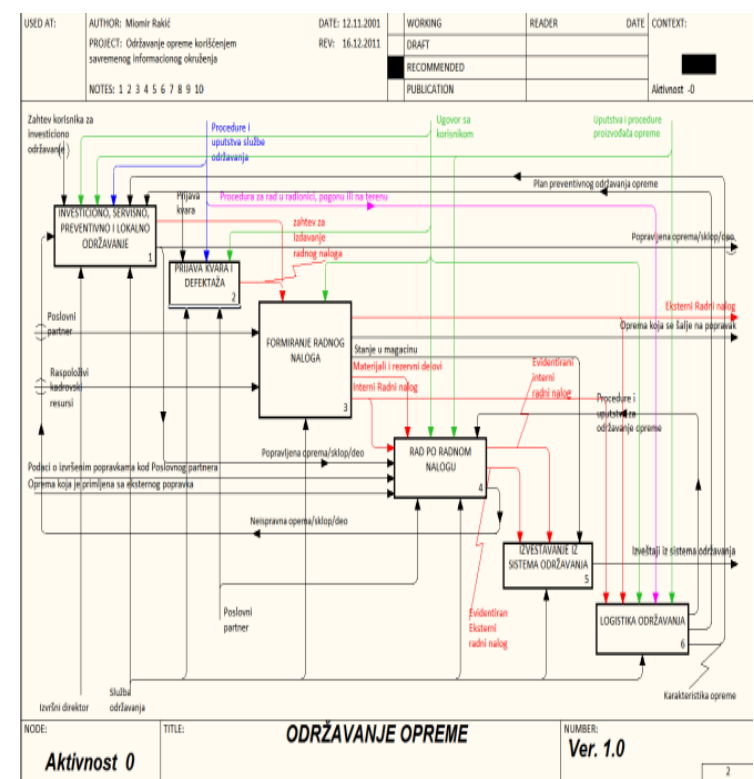

Fig 3 Example of the IDEF0 processes model diagram

All of the parameters are defined for each selected objective individually from the more perspectives. For each perspective individual assessment should be done carefully. If there is any mistake in that assessment, system won't be able to analyze process correctly.

\section{INITIAL ACTIVITIES PRECEDING PDW OPERATIVE USE IN ORDER TO ANALYZE AND IMPROVE PROCESS}

Using BPWin and Erwin [6] tools, analysis, process and data models generating, and process and objective structure models association were performed.

Then selection of objectives and success rate indicators was done. The objectives are determined based on user requirements, contractual obligations and internal requirements referring to analysis of current state of Maintenance Service, its improvement and cost reduction [7]. All of the objectives were analyzed from the aspects of basic perspectives e.g. information, organizational, functional and behavioral. The four impact factors to pattern of process changes were identified, e.g. time, cost, quality and flexibility.

Since maintenance service process performs through work order (WO), the following objectives have been selected: (1) Timely ground operation or time from defect report up to arrival to defective equipment location; (2) Time to repair defect, or time from arrival to location up to the end of repairing, and (3) Per- 
centage of yearly equipment uptime.

All of indicators are entered into the fact table. Example of fact table (F_RADNI_NALOG) is shown in Fig. 4. Table and its attributes specificity are elements enabling direct analysis and comparison of certain activities in process. In this way, a completed process with all activities entered through the frame of one relation. All parameters that indicate an objective achievement of each individual activity inside process are available for analysis, too.

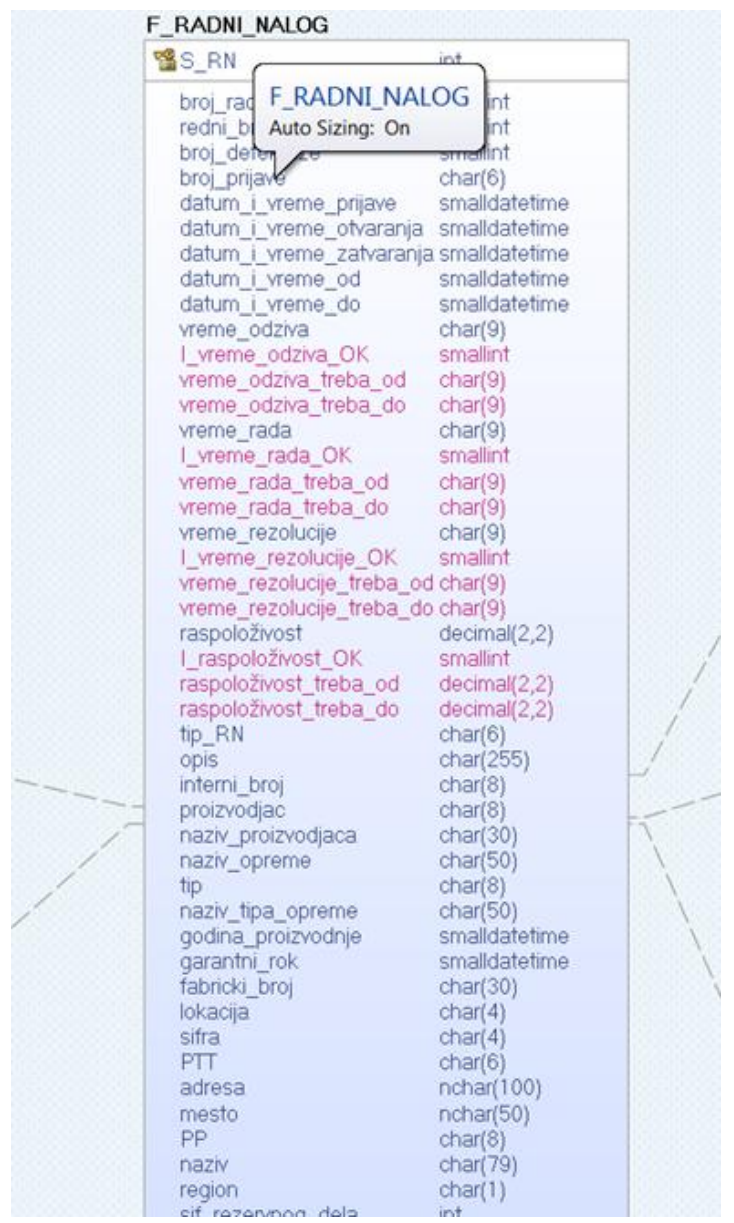

Fig 4 Objectives and indicators in fact table

Particular attention was paid to level of details that are unique for each and all parameters that describe activities inside considered process of work by work order.

\section{DEFINING SOURCE DATA LOCA- TION AND THEIR ANALYSIS}

First activity needed to analyze a process that should be done is analysis of availability and usability of data through a pilot project.

Basic data are in operative applications that follow work order realization at the transaction level.

The data for work orders analysis were located in few relation tables (e.g. RECEPTION, DEFECTATION, WORK_ORDER, EMBEDDED_PART etc.) including individual activities of the complete equipment repairing process.

All of these data that were used for analysis set through internal objectives. External objectives referring to the contractual obligation did not entered in operative applications system. There- fore, they required special analysis, defining all of their parameters, way of enter and integration with internal data. Time of ground operation and defects repairing are such kind of data.

In this case study the authors had work orders from the period of more than seven years at their disposal. In this period total number of work orders was more than 6,000 , defects - more than 14,000 , and more than 5.000 parts or assemblies embedded into equipment.

All of those data were checked additionally against reference and relationship among themselves. About $0.3 \%$ of inconsistent data has been discovered in work orders that were entered by defect determination and defect reporting. Many of them emerged in time of event at the beginning of application implementation period (2008 year).

All of those inconsistent data relations were ignored in analysis of equipment maintenance processes.

\section{SELECTION OF DATA BASE STRUC- TURE}

The DW platform has been chosen for considered process analysis in order to offer basic solutions for correction and improvement of equipment maintenance process. Then, the most appropriate DW for required analysis was selected from the basic types of DW in repository.

In the first step a multidimensional modeling was selected due to stand alone system that were isolated, including even another associated functions such as warehousing, human resources etc., which normally belonged to the other processes [8], [9]. Broadly accepted concept of multidimensional modeling was the second reason for its selection. The multidimensional DB consists of understandable data for users and it enables fast response to their requests.

As multidimensional modeling is not structured according to the rules of third normal form (3NF) of the relation DB, it enables more direct and clearer communication between designer and user [10].

Following dimensional modeling, a star scheme was selected as a sub type of multidimensional model. Since focus of this research was only at one segment of maintenance service functioning, the Kimball approach was selected instead of impossible approach in available time suggested by Inmon.

\section{DEFINING METHOD OF DIMENSION MODEL DESIGN}

Having selected Kimball principles of dimensional model design (including dimensional model and star scheme), the four following steps in DW development were applied [11]: (1) Business process selection; (2) Granularity defining; (3) Defining dimensions including methods of their maintenance from type 0 up to type 7, and (4) Defining and adopting type of Facts Table [12], [13], [14], [15]).

Confirming PDW as basis for process analysis and improvement, and checking and proving level of contractual obligation fulfillment by Service Company, was the main hypothesis in the project.

Besides general analysis in this part of paper some other analysis have been performed, such as frequency defect analysis of certain assemblies and subassemblies, frequency defect in relation to certain server and so on.

In the second step levels of data granularity were defined. These levels had to be equal for all activities in a process and for 
all objectives as well.

In third step the dimensions were defined. During users interviews particular attention was paid to attributes and adjectives that described processes and agents in them. All dimensions should have had the same granularity and the same sequence order for each activity.

\begin{tabular}{|ll}
\hline dim_datum & tel_mobını \\
\hline S_trenutak & varcnar(L \\
\hline datum & smallint \\
dan & datetime \\
naziv_dana & smallint \\
mesec & varchar(10) \\
godina & smallint \\
nedelja & smallint \\
dan_u_nedelji & smallint \\
polugodiste & smallint \\
drzavni_praznik & smallint \\
dan_pred_praznik & smallint \\
dva_dana_pred_praznik & smallint \\
neradan_dan & smallint \\
pun_opis_datuma & smallint \\
redni_broj_dana_u_epohi & datetime \\
redni_broj_nedelje_u_epohi & integer \\
redni_broj_meseca_u_eohi & integer \\
redni_broj_dana_u_mesecnom_kalendaru integer \\
redni_broj_dana_u_godisnjem_kalendaru integer \\
indikator_poslednjeg_dana_u_nedelii & integer \\
indikator_poslednjeg_dana_u_mesecu & integer \\
redni_broj_nedelje_u_godini & integer \\
kalendarski_dan_zavrsetka_nedelje & integer \\
ime_meseca_u_godini & varchar(20) \\
broj_meseca_u_godini & integer \\
broj_kvartala & integer \\
kalendarska_godina & integer \\
indikator_vikenda & integer \\
indikator_praznika & integer \\
naziv_praznika & char(100) \\
indikator_verskog_praznika & integer \\
naziv_verskog_praznika & char(100) \\
sifra_godisnjeg_doba & integer \\
naziv_godisnjeg_doba & varchar(10) \\
indikator_temperaturnog_kolapsa & integer \\
dogadjaj_velikog_znacaja & integer \\
naziv_velikog_dogadaja & char(100) \\
\hline
\end{tabular}

\section{Fig 5 Dimensional time table}

In next step the facts were defined to support metric of the processes. Then data structure and their normal range, type and measuring frequency were recognized.

Process ETL, based on classic Kimball approach, in first step extracts data from relation DB systems, using classic SQL commands and loading them to the fact tables.

Dimensional time table (shown in Fig. 5) was considered carefully due to period from 2007 to 2020 , including all holidays and previously considered period (2007 to 2014). As results of these activities many star schemes were generated.

\section{SELECTION OF PRESENTATION MODEL}

Following process of PDW generating, selection of presentation tool was performed. Microsoft Excel was selected as basic tool. Second tool, located in MSSQL Server2012, includes data mining algorithms such as decision tree, clustering, associations, linear regression, and time series etc., purposed for data analysis.

Microsoft Excel was selected as a tool for spreadsheet and graphic presentation due to relatively small set of data and limited volume. The Oracle Business Intelligence One data base was used for advanced results presentation. Compatibility between MS SQL Server 2012 and Oracle BI tools and capacity of the Oracle BI tools were confirmed in this project. Phases, methods and relations of this project are shown in Fig. 6.

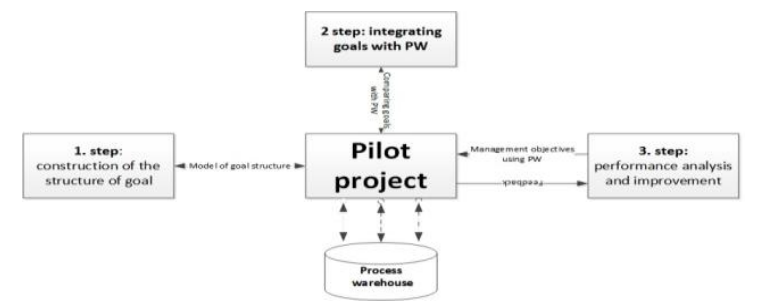

Fig 6 Phases and relations inside pilot project

Model that was supposed to support presentation process should supported structure of objective and fulfilled two basic conditions: (1) It should support process analysis and improvement (or correction) of its performance to achieve wanted objective, and (2) It should enable defining reference points for consistent interpretation of numeric values giving review of objective achievement criteria.

\section{OBJECTIVES INTEGRATION BY PDW}

Performance analysis and process improvement were main goals of this project. The performances were based on objective management, and objectives were integrated into PDW data related to process realization.

This approach required that designer of DW structure from the beginning should entered value of process objective alongside each data related to the value of success rate of process itself. These process objectives were used for PDW management during performance analysis and process improvement decision making.

Generally, PDW meta-model requires, in first step, recognition then consideration, and adoption of common concepts of business processes and operating environment.

The operating environment, as general model of business processes can be used as common meta-model for PDW designing. The operating environment consists of the four perspectives: (1) Functional; (2) Information; (2) Organizational, and (4) Behavioral.

Functional perspective is related to process elements, such as activities performed in process.

Information perspective is concerned to resources that are transmitted, consumed and produced by process elements. The resources can be material, e.g. product, or information, such as data.

Organizational perspective takes care on location from which process elements are invited and participants that invited them, and on location where process elements are executed. Main focus here is on participant that can be organizational unit, individual person or software.

Behavioral perspective takes care on time and order of activities such as loops, branching forward or back, order, simultaneity, decision making etc.

Suggested PDW specification extends to two level - conceptual and implementation. Conceptual level defines needs for understanding of PDW design specification. Physique design of PDW is represented on implementation level. 


\section{PILOT PROJECT}

Through pilot project answers to following questions were provided:

- Usability of Oracle Business intelligence One in combination with MS SQL Server 2012

- Applicability of PDW in process analysis and improvement

- Usability of objectives, bitmap indicators, range of objectives and expired data of objectives limit value

- $\quad$ Quality and accuracy of MS Office Excel analysis.

Analyzing data inside PDW can be seen that was in average, as follows:

- 2.4 defect items by work order

- 0.35 replaced parts by work order item

- 0.79 replaced parts by work order. Actually, it is 0.59 because in 2639 work orders more than one part is replaced. It indicates that almost in every second work order was necessary to replace at least one part and somewhere more than one.

These relationships indicate that:

- Proportion of mechanical defect and other types of defect is almost 1:3

- Replacement of parts was necessary at every second departure to the ground operation.

In project framework, objectives that indicate success rate of contractual obligations fulfillment or objective that should be achieved were analyzed, too. These objectives are as follows:

- Achieved condition for ATM up time

- Achieved condition for response time on defect report

- Achieved condition for defect repairing time.

Each of these objectives has been analyzed in detail from the three perspectives:

- User perspective as contractor

- Service Company perspective as contractor

- Maintenance Service perspective to optimize costs of ATM maintenance.

Each of those objectives had its validity range, success rate indicator, and validity expire time. Results of objectives achievement were analyzed from the point of the three above mentioned perspectives and three basic objectives.

From the point of decision making process and its basic five elements the following results are identified:

- Initial conditions that were extracted from operational DBs and supplemented by missing information.

- Target conditions that were adopted based on user contract parameters.

- Information related to decision such as defined values of success rate of realized business process, OK or NOK, and percentage (\%) of the ATM up time.
- Decision making process, based on previous elements and its analysis, defined decisions that should be realized in order to correct process, because process can be downgraded in one segment and improved in another.

- Change of process defining concrete change, its realization and following of decision-made realization, and results of the decision.

The following results of analysis are obtained: (1) Yearly equipment up time condition fulfillment; Condition fulfillment of timely going to equipment location, and (3) Condition fulfillment of timely defects repairing. Influence of parameters related to a day in week, seasons and their influence to frequency of defects appearance, and time limit fulfillment were additionally checked.

\section{OBJECTIVES ACHIEVEMENT ANALYSIS}

Analysis that relates to objectives achievement indicating yearly equipment up time is shown by table and graphic diagram in Fig. 7.

These results show that 202 ATMs in ownership of one user have $99.4 \%$ up time level against minimal objective, $95 \%$ increasing up to $100 \%$. This result indicates that the ATMs survived one year $100 \%$ up time without any incident thanks to regular service. Actually, the ATMs did not work only during regular maintenance service, display forms replacement, and during time of loading them by money. Those activities are not included in nonfunctional time.

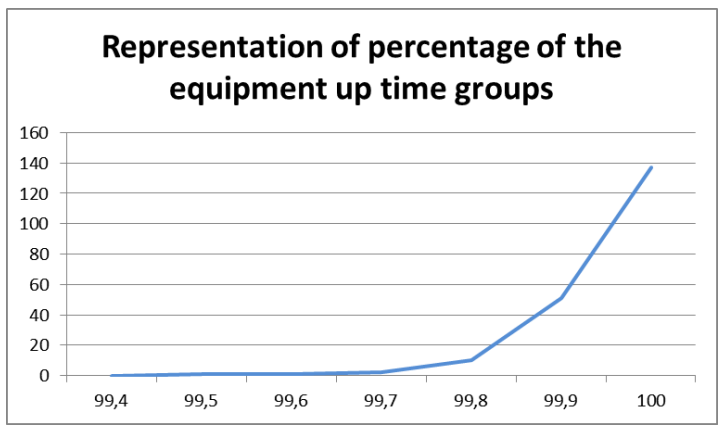

Fig 7 Diagram representation of percentage of the equipment up time groups

Based on this analysis it was confirmed that ATMs up time excided far away over yearly target value, $95 \%$. Actually, up time is moving in upper limits that are good at non detailed analysis. In fact, that was not good at all, except for banks, while it was very bad for Service Company. Simply, Service Company did not perform its process analysis quite well, and did not adopt its processes to analyzed values.

This situation can be considered from the profitability point of view. In our case, as for Service Company a very bad contract was signed with bank, because amount to be paid up from bank implied ATMs up time just a little above $95 \%$, but not almost $99.99 \%$.

The results indicate that Service Company had too many people, preventive maintenance was performing very frequently, equipment was top quality, surrounding of ATMs was of extra quality, and so on. From the profitability point of view, the Service Company was functioning poorly. Unfortunately, even this claim is not accurate that will be seen in the following chapters. 
Table 1 Review of contracted response deviation per one contracted response

\begin{tabular}{|c|c|c|c|c|c|c|}
\hline \multicolumn{6}{|c|}{ RESPONSE } & \multirow[b]{2}{*}{$\begin{array}{l}\% \text { in relation to the } \\
\text { total number of } \\
\text { intervention }\end{array}$} \\
\hline \# RN & \begin{tabular}{|c|} 
agreed \\
response \\
(hours)
\end{tabular} & NOK & OK & $\Sigma$ & $\begin{array}{l}\% \text { Delay at an } \\
\text { agreed } \\
\text { response }\end{array}$ & \\
\hline 2051 & 1 & 384 & 1668 & 2052 & $18,71 \%$ & $33,18 \%$ \\
\hline 314 & 1,5 & 73 & 241 & 314 & $23,25 \%$ & $5,08 \%$ \\
\hline 2662 & 2 & 987 & 1675 & 2662 & $37,08 \%$ & $43,05 \%$ \\
\hline 438 & 2,5 & 77 & 361 & 438 & $17,58 \%$ & $7,08 \%$ \\
\hline 182 & 3 & 32 & 150 & 182 & $17,58 \%$ & $2,94 \%$ \\
\hline 424 & 4 & 75 & 349 & 424 & $17,69 \%$ & $6,86 \%$ \\
\hline 112 & 8 & 13 & 99 & 112 & $11,61 \%$ & $1,81 \%$ \\
\hline \multirow[t]{3}{*}{6183} & 0 & 1641 & 4543 & 6184 & $26,54 \%$ & $100,00 \%$ \\
\hline & & & 6184 & & & \\
\hline & & $26,54 \%$ & $73,46 \%$ & & & \\
\hline
\end{tabular}

If these results are correlated to objectives and indicators of objectives achievement, meaning that objective of ATMs up time above $95 \%$ was fully realized, in that case up time indicator was OK. Curve on diagram should be declined at left side, while it was declined at right side in analyzed case. Range of results begins from $99.4 \%$ up to $100 \%$, but in normal conditions it should start from $95 \%$ that was contracted objective.

Primary task of any system success rate is not only whether system achieves objective, but also in which range the objective was successfully achieved. In the field such as maintenance service only equipment up time, optimal results and service expenses are paid.

Case described above is an example how process should be improved, precisely "downgrade" or to be corrected, or how conditions of contract through process analysis can be changed, and ATMs up time to $99.5 \%$ or more can be increased, and charged more, too. Results of this analysis give us basis for detailed analysis of maintenance service staff engagement, both in Central Service Office and in external Service Offices on the field, then for analysis of yearly number of preventive maintenance, cost and spare parts quality, and so on.

Table 2 Review of response time exceded per set of all work orders

\begin{tabular}{|r|r|r|}
\hline exceded per set of all WO & 1641 & $27 \%$ \\
\hline response OK & 4543 & $73 \%$ \\
\hline Total & 6184 & $100 \%$ \\
\hline
\end{tabular}

Primary task of any system success rate is not only whether system achieves objective, but also in which range the objective was successfully achieved. In the field such as maintenance service only equipment up time, optimal results and service expenses are paid.

Case described above is an example how process should be improved, precisely "downgrade" or to be corrected, or how conditions of contract through process analysis can be changed, and ATMs up time to $99.5 \%$ or more can be increased, and charged more, too. Results of this analysis give us basis for detailed analysis of maintenance service staff engagement, both in Central Service Office and in external Service Offices on the field, then for analysis of yearly number of preventive maintenance, cost and spare parts quality, and so on.

Analysis of the objective related to fulfillment of time needed for ground operation shows that there was quite big problem in achievement of that objective. Time shown in Table 1 is specific because it includes time that maintenance service staff tries to repair ATMs remotely giving advice to caller. The second specificity relates to indication of defect that maintenance service staff gets over application installed on ATM.
Table 3 Rewiew of ATM repairing per years

\begin{tabular}{|r|r|r|c|}
\hline \multicolumn{1}{|c|}{ Year } & \# WO per year & $\begin{array}{c}\text { Avg \# of WO per } \\
\text { month }\end{array}$ & Note \\
\hline 2008 & 592 & 65,8 & from IV to XII \\
\hline 2009 & 863 & $\mathbf{7 1 , 9}$ & \\
\hline 2010 & 1049 & 87,4 & \\
\hline 2011 & 1008 & 84,0 & \\
\hline 2012 & 1004 & 83,7 & \\
\hline 2013 & 989 & 82,4 & \\
\hline 2014 & 679 & 84,9 & from I to VIII \\
\hline 2014 & 1018,5 & 84,9 & 014 year (estimate) \\
\hline Average: & $\mathbf{7 5 1 , 2}$ & $\mathbf{8 0 , 0}$ & \\
\hline
\end{tabular}

Those defects maintenance service persons can remove by remote access using monitoring application. If it is successful in short time, usually bank never notices that activity. If remote defects repairing were successful, sometime with help of people from the bank, the defects were not recorded in work order at all. However, if it is unsuccessful then work order was issued.

Time of remotely repairing the ATMs defects was included in range of service time staring from defect registration up to going to the ground operation. Costs of going to the ground operation were decreased by experienced and trained maintenance service staff to repair the defects remotely, as much as possible.

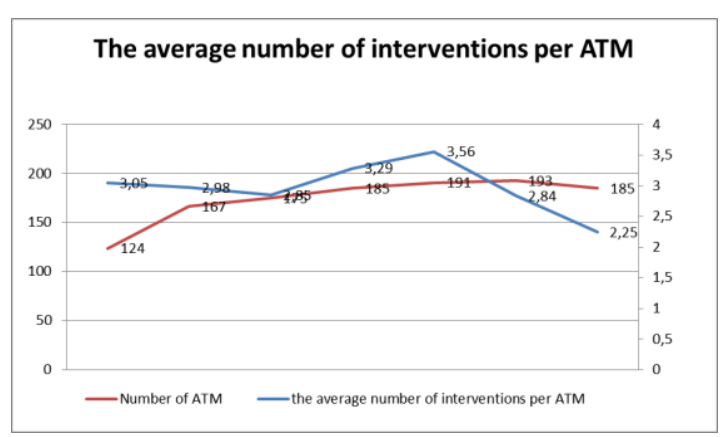

Fig 8 Average number of interventions per ATM

Dependence of average number of intervention per number of equipment and number of intervention that occurred at the same time is shown in Fig. 8. Apparently there were any extreme deviations in number and frequency of work orders. On the other side, there was great deviation in response time (Fig. 9.).

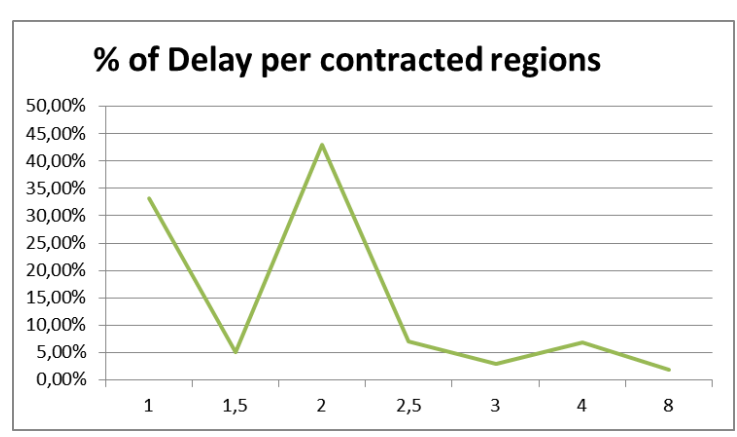

Fig 9 Response time delay in \%

It can be seen that almost $30 \%$ of on-ground time at location of defected equipment ended by delay that enabled user to charge penalties according to the contract (Table 2). Review of response delay per regions is given in Table 4 . 
Table 4 Review of deviation from contracted resolutions per regions

\begin{tabular}{|c|c|c|c|c|c|c|}
\hline \multicolumn{6}{|c|}{ RESOLUTION } & \multirow[b]{2}{*}{$\begin{array}{l}\% \text { Intervention in } \\
\text { relation to the total } \\
\text { number of Wo }\end{array}$} \\
\hline \# wo & resolution & NOK & OK & $\Sigma$ & $\begin{array}{l}\% \text { Delay at the } \\
\text { agreed } \\
\text { resolution }\end{array}$ & \\
\hline 2051 & 1 & 96 & 1956 & 2052 & $4,68 \%$ & $33,18 \%$ \\
\hline 314 & 1,5 & 23 & 291 & 314 & $7,32 \%$ & $5,08 \%$ \\
\hline 2662 & 2 & 175 & 2487 & 2662 & $6,57 \%$ & $43,05 \%$ \\
\hline 438 & 2,5 & 28 & 410 & 438 & $6,39 \%$ & $7,08 \%$ \\
\hline 182 & 3 & 9 & 173 & 182 & $4,95 \%$ & $2,94 \%$ \\
\hline 424 & 4 & 58 & 366 & 424 & $13,68 \%$ & $6,86 \%$ \\
\hline 112 & 8 & 15 & 97 & 112 & $13,39 \%$ & $1,81 \%$ \\
\hline \multirow[t]{3}{*}{6183} & & 404 & 5780 & 6184 & $6,53 \%$ & $100,00 \%$ \\
\hline & & & 6184 & & & \\
\hline & & $6,5 \%$ & $93,5 \%$ & & & \\
\hline
\end{tabular}

Analyzing individual response can be seen that in many cases delay was at closest locations to the Service Office. In Table 4, responses 1 and 2 relate to distances from 150 to $200 \mathrm{~km}$ from Service Office.

Comparison of relationship between response delay and \% of intervention is shown in Fig. 10 shows that highest number of delays there where in terms of one and two hours where there are most ATMs and interventions, as well. Those ATMs had $76 \%$ of interventions and response delays much higher than other terms (33.1\% and $43.05 \%)$, e.g. every second intervention at response in two hours delayed. Results of defects repairing are much better for Service Company.

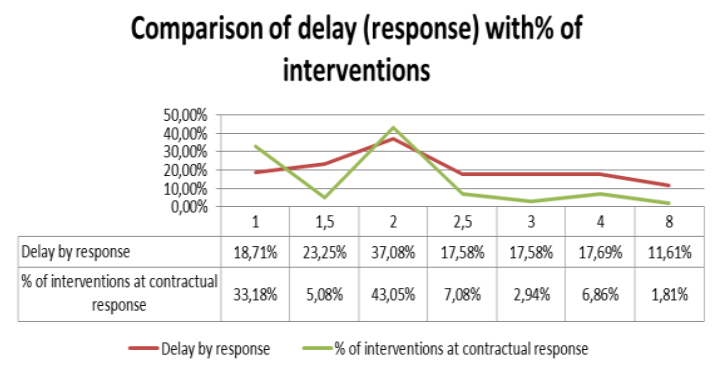

Fig 10 Comparison between response delay and \% of interventions

In achievement of this objective, problem of delayed realization is much less then going to ground operation. Namely, only $6.5 \%$ of cases maintenance service staff didn't achieve contracted objectives and they exceeded time of defect repairing.

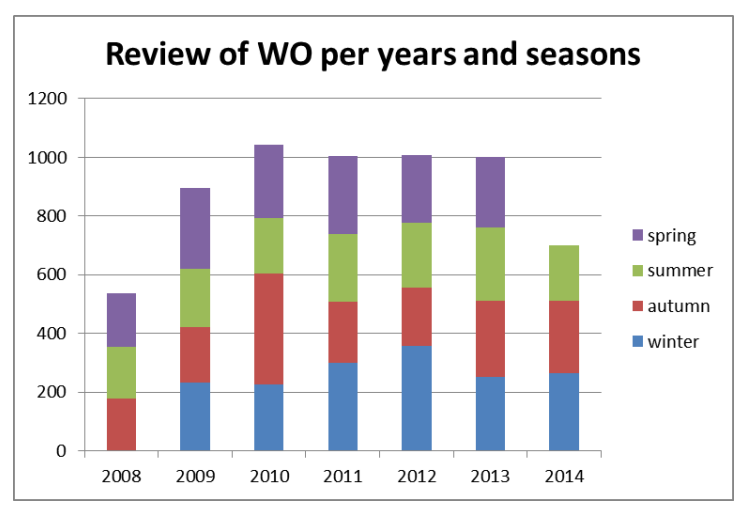

Fig 11 Review of WO number per years and seasons

Additionally parameters related to day in week and seasons are analyzed, too. Results of the analysis show that neither day in week nor seasons do not affect standard deviation in great extent (Fig. 11 and Fig.12).

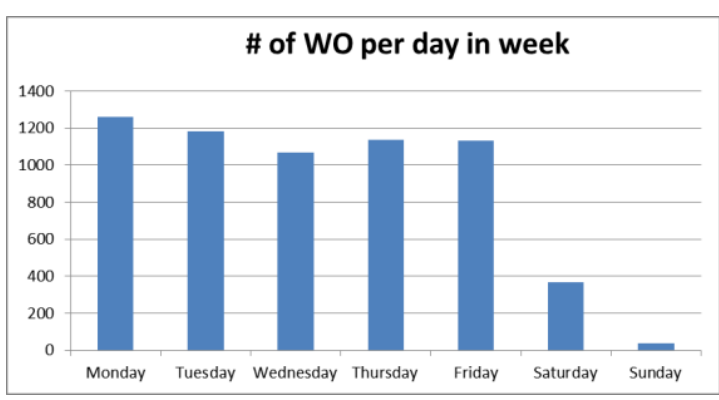

Fig 12 Number of WO per days and week

\section{CONCLUSION AND FUTURE WORK}

In this paper an approach to detailed and possible analysis of business processes (DW, data mining and their combination) is described. Then, a review of modeling languages for business processes is given, and models, as basis for process performance assessment are generated. Methodology of data structuring, including data warehousing and basic concepts such as fact table and dimensions are described in detail, too. Reasons for choice of Kimball's method are given. Then, elements and characteristics of process data warehouse, as basis for process analysis are described through methodology and structure of DW concepts related to PDW. Goal Driven type of PDW, based on achievement of set up objectives is chosen, among other types of PDW.

Based on detailed analysis of the available processes, some processes and activities were chosen and described, such as an appropriate PDW structure and method of dimension model design. The objectives, success rate indicators and locations of data for PDW loading, and complex ETL procedure, were defined, too. Finally, an optimal presentation model for this project was selected.

In next step, the objectives of chosen processes, their limit values, bit map indicators of success rate of the objectives achievement and expire date of objectives values were determined. Integration of chosen test process and its objectives was performed at the levels of dimension tables and business model, including results of process performances. All agents that affect success rate of process performances were recognized.

Individual and summarized detailed analysis of the success rate of observed process and its objective achievement in relation to yearly ATMs up time, timely ground operation and defect repairing time indicated completely contradictory results of Service Company success rate, going from $100 \%$ up to $30 \%$ cases of delayed interventions. Factors of the potential effect to the results of analysis, such as day in week, seasons and number and age of ATMs, were additionally reviewed. Summarized results of the objectives achievement from the User, Service Company and Maintenance Service point of view, were given through success rate indicators, time of expired validity, and time of parameters validity.

Results of functioning Maintenance Service indicated that Bank was most satisfied due to extra income from the paid off penalties. Having contract for ATMs maintenance and some income, Service Company was satisfied, too. However, Maintenance Service failed almost in all parameters.

Apparently, Service Company could increase contracted price due to achieved $100 \%$ of the ATM up time instead of $95 \%$ contracted, and could change time of ground operation, between request and start of intervention, too. Maintenance Service could analyze reasons of so high percentage of the ATMs up time and align its activities to the contracted obligations (a little above $95 \%$ ), and could find out causes of ground operation delay, too. 


\section{REFERENCES}

[1] Rakić, „Data Warehouse Architecture in OpenSystems, "XIII Naučno-stručni skup INFO-TEH '98, Zbornik radova, ISBN 86-82831-03-01, Vrnjačka Banja, 15.-19. jun, 1998, pp. 163-166, 1998

[2] M. Mohsen / M. B. Muriati, „Theoretical and Conceptual Approach for Evaluation Business Process Modelling Languages," Journal of Convergence Information Technology (JCIT), 2013.

[3] M. Rakić, „Karakteristika i ocena upotrebljivosti IDEF0 i IDEF1X metoda za projektovanje informacionih sistema,“ u Info Tech '97, Vrnjačka banja, 1997.

[4] H. Takeda, P. Veerkamp, T. Tomiyama / H. Yoshikawa, „Modeling Design Process,“ AI Magazine Winter, pp. 37 48, 1990.

[5] B. Curtis, M. I. Kellner, Over / I, „Process Modeling,“ Communications of ACM, t. 35, br. 9, pp. 75 - 90, 1992.

[6] C. Associates, „CA ERwin Data Modeler Standard Edition,“ Computer Associates, 114 2014. [Na mreži]. Available: http://erwin.com/products/datamodeler/standard-edition. [Poslednji pristup 114 2014].

[7] L. L. Reeves, A Manager's Guide to Data warehousing, Indianapolis, IN: Wiley Publishing, Inc., 2009.

[8] M. Ross, „The 10 Essential Rules of Dimensional Modeling," $\quad[\mathrm{Na}$ mreži]. Available: http://www.kimballgroup.com/2009/05/29/the-10-essentialrules-of-dimensional-modeling/. [Poslednji pristup 153
2014].

[9] M. Rakić / T. Petrović, „Optimization of reporting using OLAP model and Business intelligence on the example of Post applications in Post of Montenegro," InfoFest, Budva, Montenegro, 2007, 2007.

[10] A. Kirk, Data Visualization: a successful design process, Birgmingham, UK: Packt Publishing, Ltd., 2012.

[11] R. Kimball, „Four-Step Dimensional Design Process,“ 2013. $[\mathrm{Na}$ mreži $] . \quad$ Available: http://www.kimballgroup.com/data-warehouse-businessintelligence-resources/kimball-techniques/dimensionalmodeling-techniques/four-4-step-design-process/. [Poslednji pristup 143 2014].

[12] R. Kimball / M. Ross, The Data Warehouse Toolkit, Indianapolis, IN: John Wiley \& Sons, Inc., 2013.

[13] R. Kimball / M. Ross, The Kimbal Group Reader, Indianapolis, IN: Wiley Publishing, Inc., 2010.

[14] K. Group, „Design Tip \#152 Slowly Changing Dimension Types 0, 4, 5, 6 and 7,“ Kimball Group, 52 2013. [Na mreži]. Available: http://www.kimballgroup.com/2013/02/05/design-tip-152slowly-changing-dimension-types-0-4-5-6-7/[Poslednji pristup 143 2014].

[15] R. Kimball, „Slowly Changing Dimensions,“ Kimball Group, $\quad[\mathrm{Na}$ mreži $] . \quad$ Available: http://www.kimballgroup.com/1996/04/02/slowlychanging-dimensions-2/. [Poslednji pristup 143 2014]. 